\title{
Spatial Distribution of Groundwater Level Changes Induced by the 2006 Hengchun Earthquake Doublet
}

\author{
Yeeping Chia ${ }^{1, *}$, Jessie J. Chiu ${ }^{2}$, Po-Yu Chung ${ }^{1}$, Ya-Lan Chang ${ }^{1}$, \\ Wen-Chi Lai ${ }^{3}$, and Yen-Chun Kuan ${ }^{4}$ \\ ${ }^{1}$ Department of Geosciences, National Taiwan University, Taipei, Taiwan, ROC \\ ${ }^{2}$ Atomic Energy Council, Taipei, Taiwan, ROC \\ ${ }^{3}$ Department of Resources Engineering, National Cheng Kung University, Tainan, Taiwan, ROC \\ ${ }^{4}$ Water Resources Agency, Taipei, Taiwan, ROC
}

Received 22 October 2007, accepted 10 January 2008

\begin{abstract}
Water-level changes were observed in 107 wells at 67 monitoring stations in the southern coastal plain of Taiwan during the $2006 \mathrm{M}_{\mathrm{w}} 7.1$ Hengchun earthquake doublet. Two consecutive coseismic changes induced by the earthquake doublet can be observed from high-frequency data. Observations from multiple-well stations indicate that the magnitude and direction of coseismic change may vary in wells of different depths. Coseismic rises were dominant on the southeast side of the costal plain; whereas, coseismic falls prevailed on the northwest side. In the transition zone, rises appeared in shallow wells whilst falls were evident in deep wells. As coseismic groundwater level changes can reflect the tectonic strain field, tectonic extension likely dominates the deep subsurface in the transition area, and possibly in the entire southern coastal plain. The coseismic rises in water level showed a tendency to decrease with distance from the hypocenter, but no clear trend was found for the coseismic falls.
\end{abstract}

Key words: Earthquake, Groundwater level, Coseismic change, Tectonic strain

Citation: Chia, Y., J. J. Chiu, P. Y. Chung, Y. L. Chang, W. C. Lai, and Y. C. Kuan, 2009: Spatial distribution of groundwater level changes induced by the 2006 Hengchun earthquake doublet. Terr. Atmos. Ocean. Sci., 20, 315-324, doi: 10.3319/TAO.2008.01.10.01(TT)

\section{INTRODUCTION}

Two consecutive earthquakes with the same magnitude $\mathrm{M}_{\mathrm{w}} 7.1$ occurred offshore of the southern tip of Taiwan at 20:26 and 20:34 local time (12:26 and 12:34 GMT) on 26 December 2006. As shown in Fig. 1, the epicenter of the first submarine earthquake is located near $21.69^{\circ} \mathrm{N}, 120.56^{\circ} \mathrm{E}$ at a depth of $44 \mathrm{~km}$, approximately $39 \mathrm{~km}$ southwest of Hengchun, and the second one is located near $21.97^{\circ} \mathrm{N}$, $120.42^{\circ} \mathrm{E}$ at a depth of $50 \mathrm{~km}$, approximately $33 \mathrm{~km}$ west of Hengchun (Central Weather Bureau 2006). The preliminarily inferred focal mechanism solutions suggest normal faulting for the first shock and strike-slip faulting for the second (US Geologic Survey 2006). In addition to human casualties and building collapse on land during the earthquake, eight international submarine cables offshore of southern Taiwan were damaged within 14 hours after the earth- quakes, disrupting telecommunications among many Asian countries (NCDR and NCREE 2006).

The 2006 Hengchun earthquake was the largest offshore earthquake ever recorded off southwestern Taiwan since modern earthquake observation began in 1896. Water level rises and falls induced by the earthquake were observed in 107 wells in the southern coastal plain. As groundwater level change can be an indicator of crustal strain (Bredehoeft 1967; Wakita 1975), the distribution of coseismic water level changes may reflect the strain field induced by fault movement. Here we use records of multiple-well stations to report groundwater level changes induced by the Hengchun earthquake and demonstrate the spatial distribution of coseismic changes in the southern coastal plain of Taiwan.

\footnotetext{
* Corresponding author

E-mail: ypc@ntu.edu.tw
} 


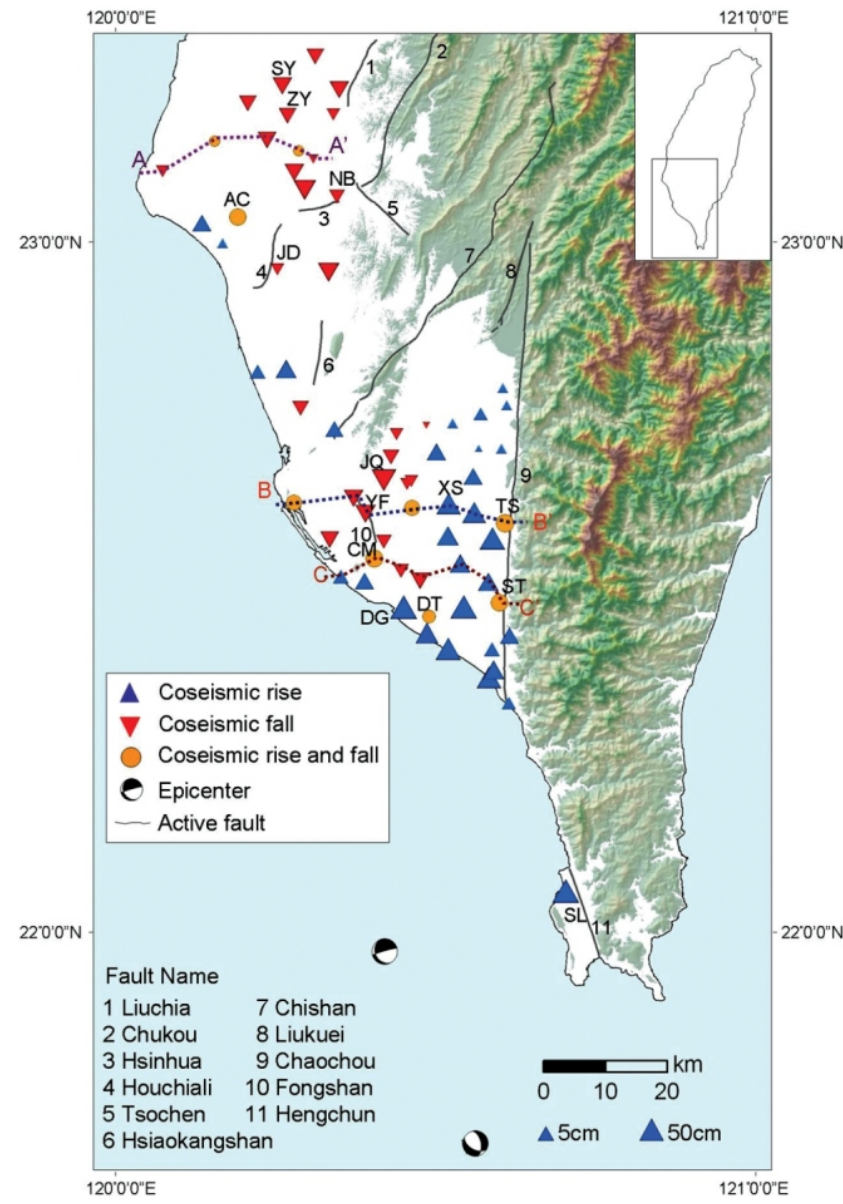

Fig. 1. Distribution of coseismic rises and falls at 67 monitoring stations in Taiwan due to the 2006 Hengchun earthquake doublet. The size of circles or triangles, on a logarithmic scale, represents the magnitude of the largest coseismic change at each station.

\section{THEORETICAL BASIS OF COSESIMIC CHANGE}

Groundwater level in an aquifer normally changes in response to variations in loading due to tides and barometric pressure (Bradehoeft 1967). During earthquakes, oscillatory changes of well water levels in response to passing seismic waves are commonly observed. Such changes are related to the flow between water in the well and pore water in the aquifer. Analytical solutions for the amplitude of the water level oscillations are determined by aquifer properties, dilatational strain associated with the passage of seismic waves, and well structure (Cooper et al. 1965; Liu et al. 1989; Ohno et al. 1997). Oscillatory changes in water level usually recover shortly after the passage of seismic waves.

Sustained coseismic rises or falls depend on whether the pore pressure of the connected aquifer is under compression or expansion as a result of the redistribution of the stress-strain field induced by fault displacement (Wakita 1975; Muir-Wood and King 1993; Roeloffs 1988). The occurrence of sustained coseismic water level change can be explained by a coupled process of elastic deformation and pore water diffusion (Biot 1941, 1955). If the effect of shear stress on pore pressure change is ignored, the generation or dissipation of excess pore pressure in deformable porous medium is controlled by the groundwater flow and the change of mean confining stress (Palciauskas and Domenico 1989):

$$
\frac{\partial \mathrm{P}}{\partial \mathrm{t}}=\frac{\mathrm{K}}{\rho_{\mathrm{w}} \mathrm{g}\left(\beta_{\mathrm{p}}+\mathrm{n} \beta_{\mathrm{w}}\right)} \nabla^{2} \mathrm{P}+\frac{\beta_{\mathrm{p}}}{\beta_{\mathrm{p}}+\mathrm{n} \beta_{\mathrm{w}}} \frac{\partial \sigma}{\partial \mathrm{t}}
$$

where $P$ is the excess pore pressure; $\sigma$ is the mean confining stress; $\mathrm{K}$ is the hydraulic conductivity; $\rho_{\mathrm{w}}$ is the density of water; $\mathrm{n}$ is the porosity; $\beta_{\mathrm{P}}$ is the porous medium compressibility; and $\beta_{\mathrm{W}}$ is the water compressibility. $\beta /\left(\beta_{\mathrm{p}}+\mathrm{n} \beta_{\mathrm{W}}\right)$ is known as the Skempton coefficient B.

As the sustained coseismic water level change occurs within a very short period of time after the earthquake, the effect of groundwater flow can be ignored. Consequently, the coseismic pore pressure change at any point is determined primarily by the change of local mean confining stress and the Skempton coefficient of the aquifer. After the occurrence of an earthquake, the change in confining stress induced by fault displacement becomes small and can be ignored. According to Eq. (1), the change in pore pressure is primarily controlled by groundwater flow. Thus, the coseismic change in groundwater level is the result of the loading effect; whilst, post-seismic change in groundwater level is related to the hydrologic process.

\section{OBSERVED COSEISMIC CHANGES}

In the southern coastal plain of Taiwan, 238 wells have been installed at 98 evenly-distributed monitoring stations since 1995. Each station consists of one to four wells with 6" casing screened at different depths. The southern coastal plain is primarily composed of thick unconsolidated or semi-consolidated deposits. Hydrogeologic investigations, including: core logging, borehole geophysical logging, sediment analysis, water quality analysis, and hydraulic testing, have been conducted for each monitoring station (Central Geological Survey 2002). Nearly all wells are screened in sand or gravel layers. Water level is recorded at one-hour intervals for each well. In addition, a high sampling rate of every two minutes has been adopted in five wells for monitoring earthquake activities.

Based on the hourly records of 238 wells, 107 wells located at 67 stations observed coseismic changes in well water level during the Hengchun earthquake (see Appendix 1). The largest coseismic rise, $54 \mathrm{~cm}$, was observed in the No. 2 well of the She-Liao (SL) station (Fig. 2a). SL, the southernmost monitoring station in Taiwan, is the closest station to the epicenters of the earthquakes. The largest coseismic fall, 

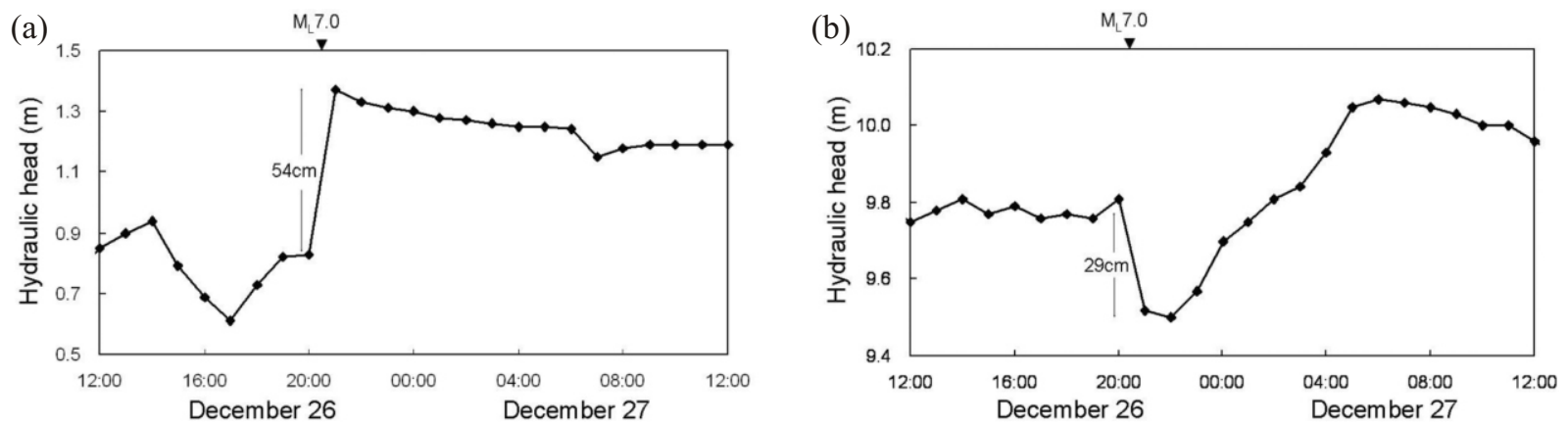

Fig. 2. Coseismic changes during the earthquakes: (a) The largest coseismic water level rise of $54 \mathrm{~cm}$ in the SL2 well; (b) The largest water level fall of $29 \mathrm{~cm}$ in the JQ1 well.

$29 \mathrm{~cm}$, was observed in the No. 1 well of the Jiu-Qu (JQ) station (Fig. 2b). In essence, the coseismic change from 20:00 to 21:00 represents the combined effects of two water level changes induced by two consecutive earthquakes at 20:26 and 20:34. The individual processes of the two coseismic water level changes during the earthquake doublet cannot be identified.

The two-minute sampling of the water level, however, can be used for observing detailed processes of coseismic groundwater level changes. Figure 3 shows the variation of water levels from 19:30 to 21:30 December 26 in four of the wells where high-frequency sampling was conducted. Sustained coseismic changes can be identified in the four wells (TS3, JD3, NB3, and ZY2) during the Hengchun earthquake doublet. The variation of water level in the TS3 well shows two consecutive sustained coseismic falls of 3.2 and $15.5 \mathrm{~cm}$. The pulse-like change between 20:26 and 20:30 was caused by oscillation of water level due to the passing earthquake waves of the first shock. In JD3, and NB3, two pulse-like oscillatory changes were observed in each well due to the passing seismic waves of the two consecutive earthquakes. The sustained coseismic fall after two consecutive earthquakes was approximately $1 \mathrm{~cm}$ in JD3 and $0.5 \mathrm{~cm}$ in NB3. In the ZY2 well, two pulse-like oscillatory changes were observed, but sustained changes could not be identified. Apparently high-frequency sampling of the water level has the advantage of observing two consecutive water level changes during the earthquake doublet.

Observations at multiple-well stations revealed vertical variations in groundwater level change during the earthquakes. Figure 4a shows variation in the water level in the four wells of the Xi-Shi (XS) station during the earthquakes. Coseismic rises observed in XS1, XS2, XS3, and XS4 were $26,25,21$, and $12 \mathrm{~cm}$, respectively. The coseismic rise was $53 \mathrm{~cm}$ in DG1, $29 \mathrm{~cm}$ in DG2, and $50 \mathrm{~cm}$ in DG3 (Fig. 4b). Figure 5a shows variation in water levels at the Sha-Ying (SY) station. Coseismic fall was $8 \mathrm{~cm}$ in SY2 and $7 \mathrm{~cm}$ in SY4, while coseismic change cannot be identified in SY1 and SY3. At the Yun-Fang (YF) station, the coseismic fall was $4 \mathrm{~cm}$ in $\mathrm{YF} 2$ and $12 \mathrm{~cm}$ in $\mathrm{YF}$ 3, while no coseismic
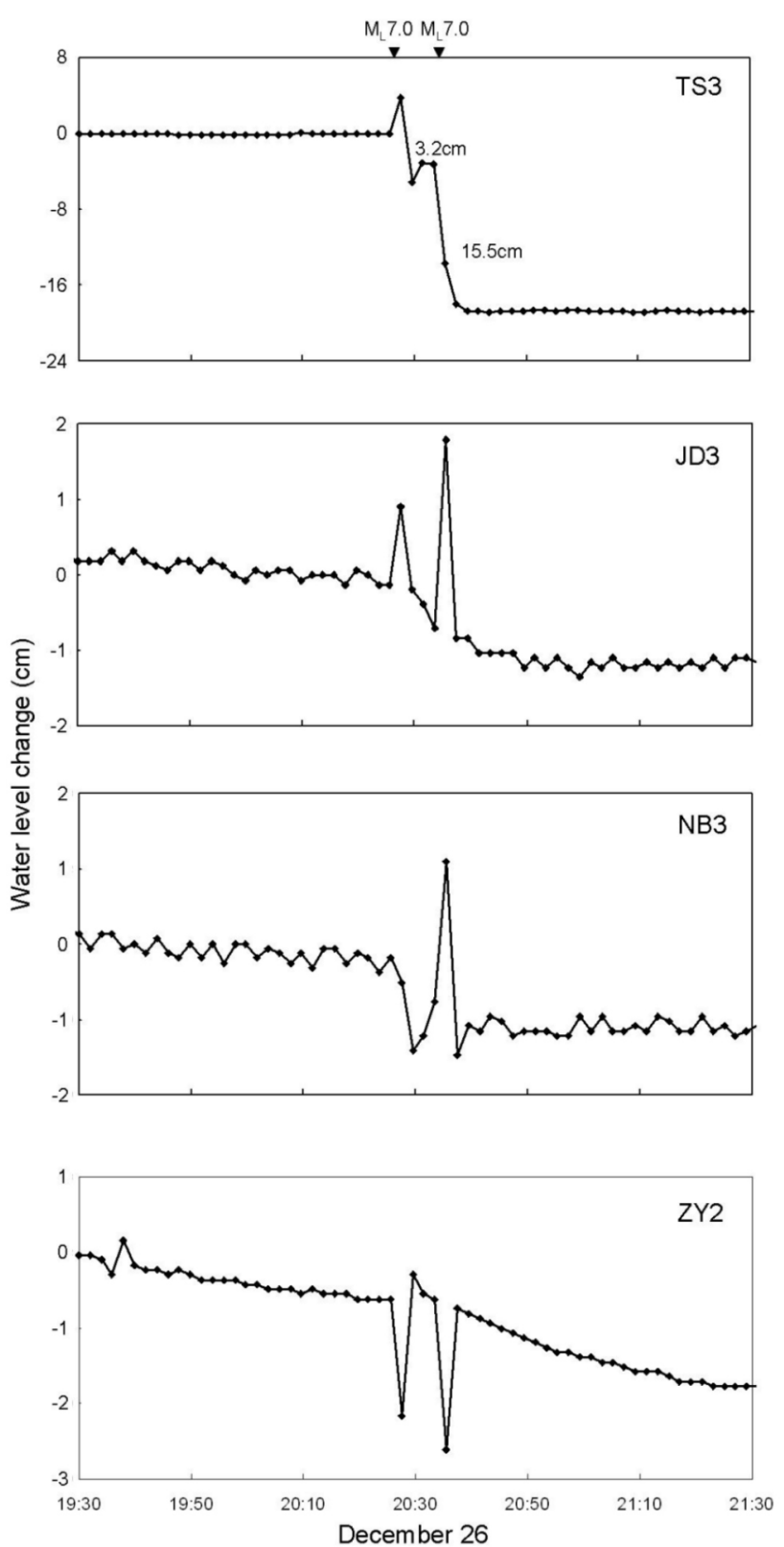

Fig. 3. Two-minute data of water level from 19:30 to 21:30 December 26 in the TS3, JD3, NB3, and ZY2 wells showing two consecutive coseismic changes during the earthquake doublet. 

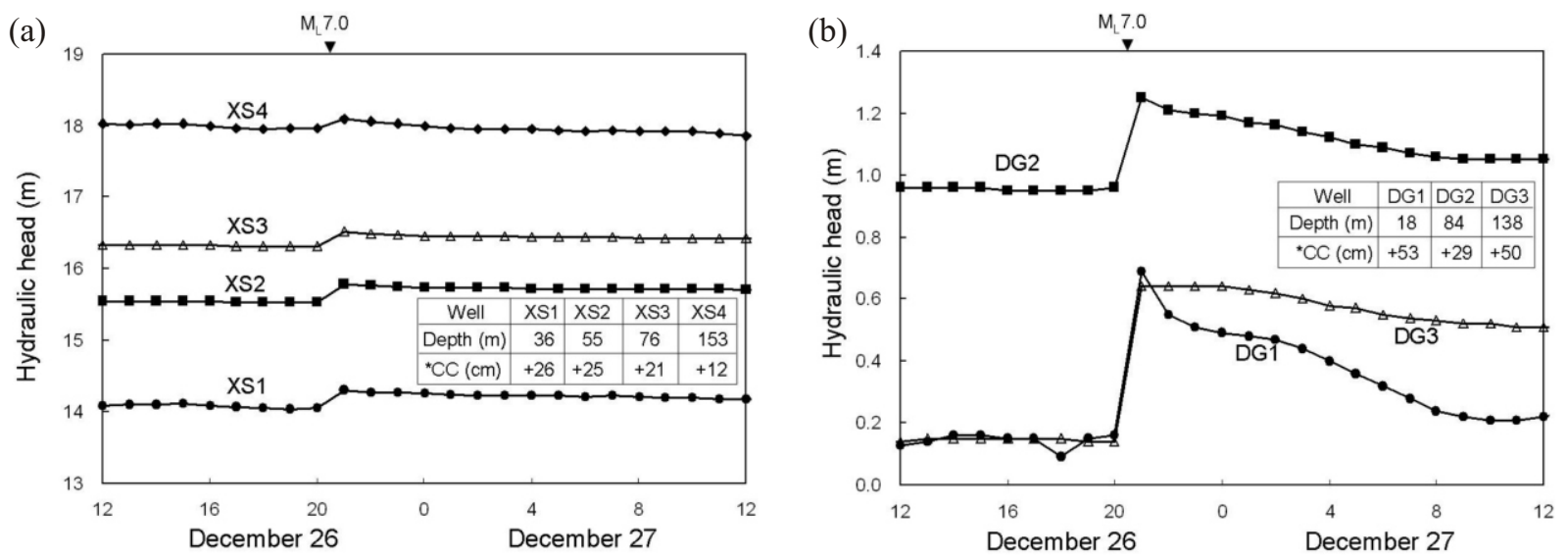

Fig. 4. Variations of water level at two stations where coseismic rises were observed during the earthquakes: (a) The XS station; (b) The DG station.
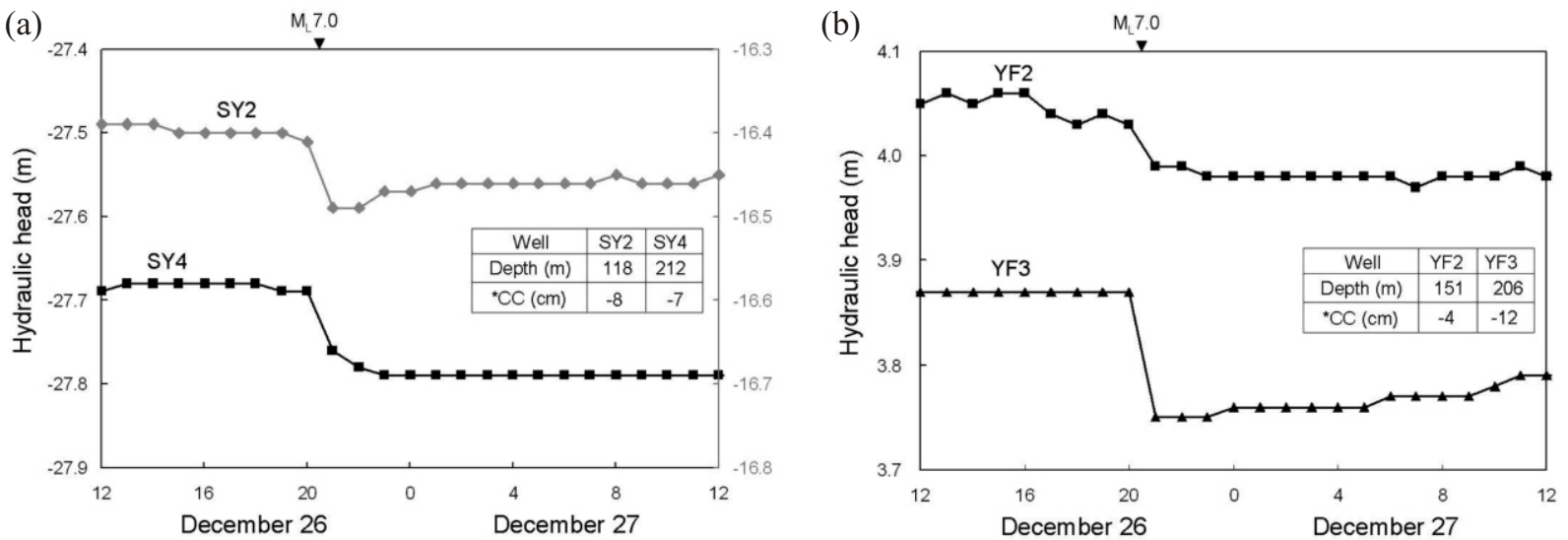

Fig. 5. Variations of water level at two stations where coseismic falls were observed during the earthquakes: (a) The SY station; (b) The YF station.

change can be identified in YF1 (Fig. 5b). Therefore, at a multiple-well station, the magnitude of coseismic water level change may vary in wells of different depths. According to Eq. (1), the coseismic change is primarily controlled by the physical properties of aquifers and the stress change induced by fault displacement. The difference in the magnitude of cosiesmic changes in the vertical implies variations in either local stress change or aquifer properties.

Both coseismic rise and coseismic fall were observed in wells of different depths at some stations. As shown in Fig. 1, most of these stations are located in the transition zone between stations where either rises only or falls only were observed. For instance, water level data at the ChaoMing (CM) station demonstrate a coseismic rise of $17 \mathrm{~cm}$ in CM1, but a coseismic fall of 9, 10, and $10 \mathrm{~cm}$ in $\mathrm{CM} 2, \mathrm{CM} 3$, and CM4, respectively (Fig. 6a). The Tse-Shan (TS) and Shan-Tan (ST) stations are two exceptions. They are surrounded on the west side by stations where only coseismic rises were observed and bounded on the east side by the Tsao-Chou fault. The fault is located along the boundary between rock formations and unconsolidated deposits.
Hourly water level data at TS show a coseismic rise of $6 \mathrm{~cm}$ in TS1, but a coseismic fall of $18 \mathrm{~cm}$ in TS3 (Fig. 6b). Therefore, the direction of coseismic changes induced by the earthquake may vary vertically at a given station. This phenomenon is likely caused by variations in local stress changes. Such changes can be induced by local boundary conditions, in addition to fault displacement (Ge and Stover 2000).

\section{SPATIAL DISTRIBUTION OF COSESISMIC CHANGES}

Based on hourly groundwater level data in southern Taiwan, 238 wells were functional during the Hengchun earthquake. Of those, sustained coseismic water level changes were observed in 107 wells at 67 stations located approximately 43 to $178 \mathrm{~km}$ from the epicenter of the first shock. Oscillatory changes could not be identified on hourly records because they disappeared shortly after earthquake waves passed through. Sustained coseismic changes in the remaining 131 wells were difficult to identify mainly due to 

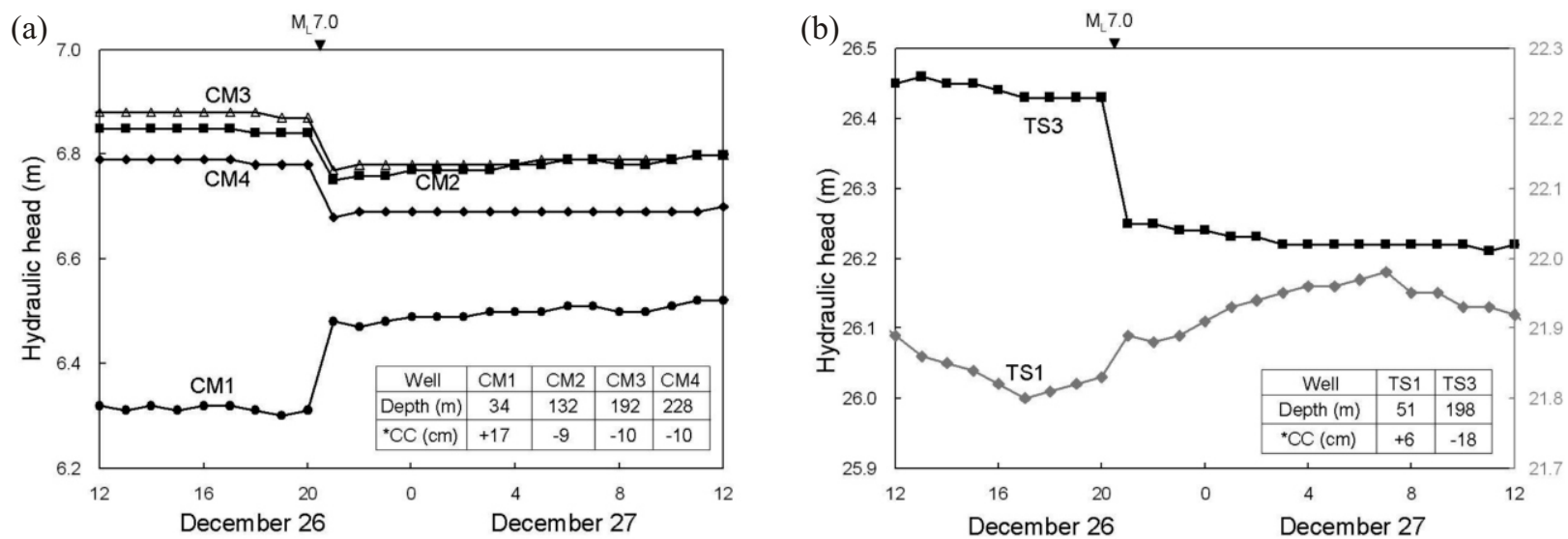

Fig. 6. Variations of water level at two stations where both the coseismic rises and the coseismic falls were observed during the earthquakes: (a) The CM station; (b) The TS station.

nearby pumping activities. As illustrated in Fig. 1, the earthquake-related well water level data revealed a preliminary framework of spatial distribution of coseismic changes in the southern coastal plain. We found that coseismic rises, ranging from 1 to $54 \mathrm{~cm}$ in 57 wells at 31 stations, dominated in the southeast side, whereas coseismic falls, ranging from -1 to $-29 \mathrm{~cm}$ in 50 wells at 27 stations, prevailed in the northwest side of the plain. Both coseismic rises and coseismic falls were observed in wells of different depths at the remaining nine stations. A similar observation was also found during the $1999 \mathrm{M}_{\mathrm{w}}$ 7.6 Chi-Chi earthquake (Chia et al. 2001).

Under the undrained coseismic condition, the change in pore pressure in an elastic porous medium can also be related to coseismic strain (Rice and Cleary 1976; Roeloffs and Quilty 1997):

$\Delta \mathrm{P}=-\mathrm{BK}_{\mathrm{u}} \varepsilon$

where $\Delta \mathrm{P}$ is the change in pore pressure; $\mathrm{K}_{\mathrm{u}}$ is the undrained bulk modulus of the aquifer; $\varepsilon$ is the volumetric strain; and the Skempton coefficient B is the ratio of the pore water pressure change to the stress change under undrained conditions. The parameter B approaches 1 for unconsolidated deposits, but becomes smaller for rigid rocks. Thus, the spatial distribution pattern of coseismic groundwater level changes due to the earthquake is indicative of the pattern of coseismic strain field induced by fault displacement.

Figure 7 illustrates the vertical distribution of coseismic changes in monitoring wells along cross-sections AA', BB', and $\mathrm{CC}^{\prime}$ shown in Fig. 1. We found that the magnitude of coseismic changes varied in the vertical direction at most stations where only rises or only falls were observed, but no trend of increase or decrease was observed with depth. Besides which, it is not sure whether the direction of coseismic change observed in monitoring wells, ranging in depth from
12 to $268 \mathrm{~m}$, can be found in the deeper subsurface. Along the three cross-sections, both coseismic rises and falls were
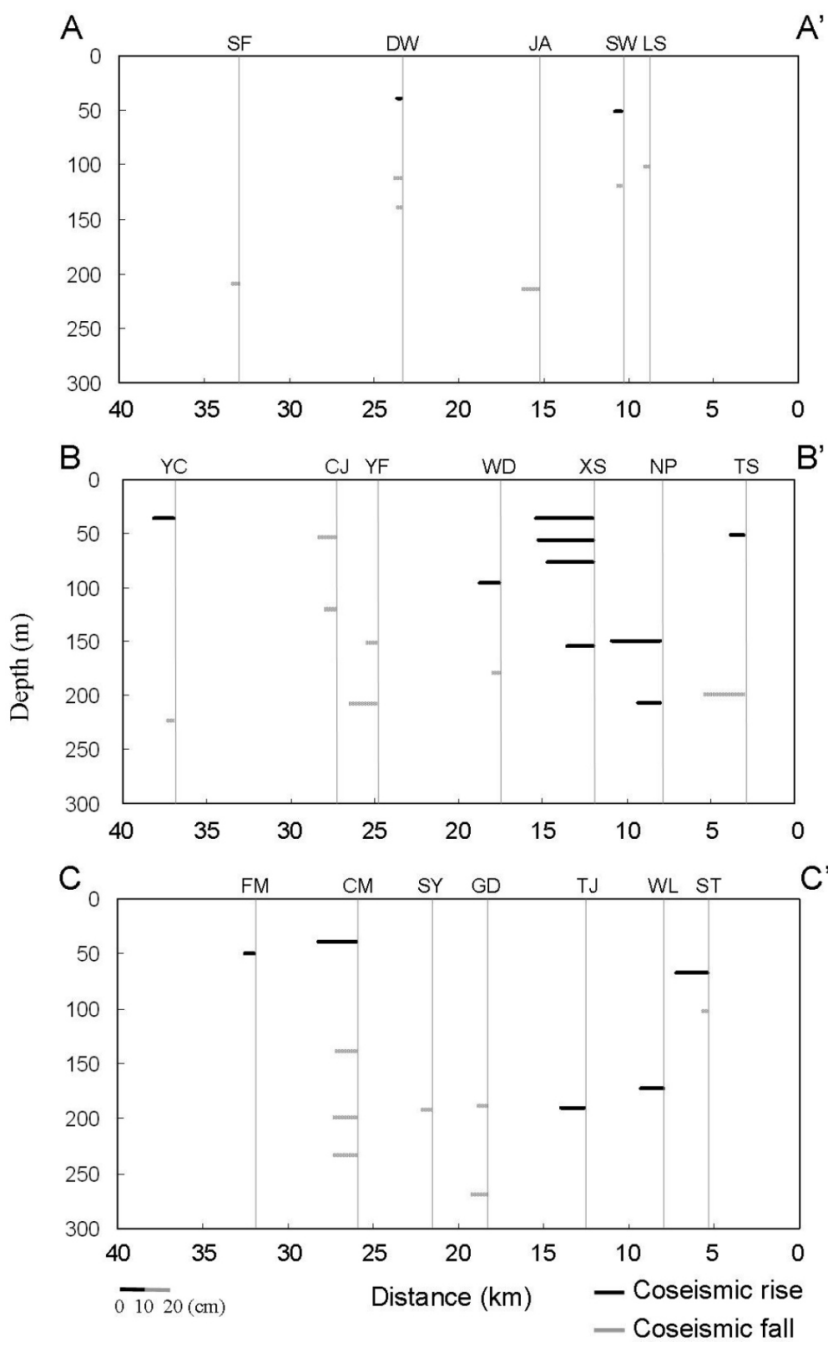

Fig. 7. Vertical distribution of coseismic changes in monitoring wells along cross sections AA', BB', and CC' shown in Fig. 1. 
observed at seven stations. At these stations, the coseismic fall typically appeared in the deep well while coseismic rise appeared in the shallow well. Similar observations were found at two other such stations, namely, AC and DT. If such a vertical distribution pattern of coseismic water level change was typical in southern Taiwan, then coseismic falls were possibly dominant in the deep subsurface of the stations where only coseismic rises were observed.

The scatter plot of coseismic change against distance from the hypocenter of the first shock is shown in Fig. 8. Due to variation in local geologic and topographic conditions, a simple relation of coseismic rise or fall to hypocentral distance is not expected (Roeloffs 1998). The largest coseismic rise observed at SL is the closest to the epicenter. Generally the magnitude of coseismic rise tends to decrease exponentially with increasing hypocentral distance. However, due to the variation of coseismic rises in wells of different depths at most multiple-well stations, the squared correlation coefficient of the best-fit regression curve is only 0.52 . Coseismic falls of a magnitude greater than $10 \mathrm{~cm}$ were scattered from a hypocentral distance of 105 to $162 \mathrm{~km}$. The largest fall observed at JQ is approximately $116 \mathrm{~km}$ from the hypocenter. Unlike the coseismic rises, there is no clear trend in the scatter plot of the coseismic falls against hypocentral distance.

\section{CONCLUSIONS}

Water level data recorded in 107 wells during the 2006 Hengchun earthquake provide a preliminary spatial distribution of coseismic changes in the southern coastal plain of Taiwan. Two consecutive coseismic changes induced by the earthquake doublet can be observed from high-fre-

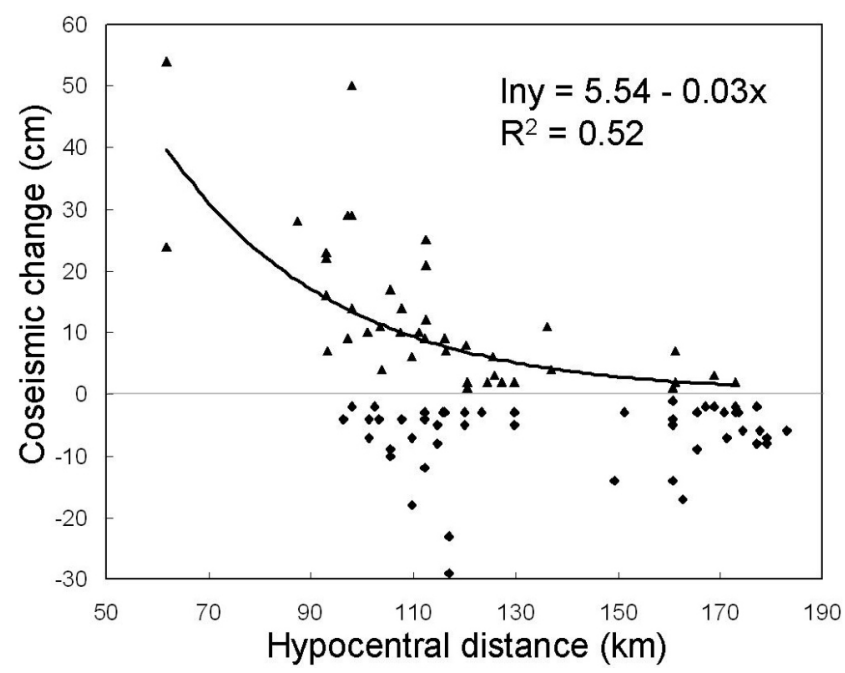

Fig. 8. Scatter plot of coseismic rises and coseismic falls versus hypocentral distance. Here the coseismic changes in unconfined aquifers are excluded because they reflect only a fraction of the actual changes. quency data. At most multiple-well stations, we found vertical variations in the direction and magnitude of coseismic water level changes. This suggests that observations in the shallow subsurface cannot be extrapolated to the deep subsurface. The vertical variations of coseismic water level changes raise the issue of validity of interpreting strain field using other monitoring devices, such as borehole strainmeter and GPS, in the shallow subsurface.

Coseismic rises and falls were found to dominate, respectively, in the southeast side and northwest side of the plain. In the transition zone, the coseismic fall appeared in the deep well whereas coseismic rise was observed in the shallow well. As the spatial distribution of coseismic groundwater level changes can reflect the strain field induced by fault displacement, tectonic extension was likely to dominate the deep subsurface in the transition zone. However, further evidence in structural geology and seismology is needed to verify whether the coseismic fall or tectonic extension prevailed in the deep subsurface of the area where only coseismic rises were observed.

Acknowledgements We gratefully acknowledge access to monitoring records and hydrogeologic information of the Water Resources Agency and the Central Geological Survey of Taiwan. We also thank two anonymous reviewers for their constructive comments. This work is supported by the National Science Council of Taiwan (NSC-94-2116-M002-011) and the Water Resources Agency (MOEAWRA0950187).

\section{REFERENCES}

Biot, M. A., 1941: General theory of three-dimensional consolidation. J. Appl. Phys., 12, 155-164, doi: 10.1063/ 1.1712886. [Link]

Biot, M. A., 1955: Theory of elasticity and consolidation for a porous anisotropic solid. J. App. Phys., 26, 182-185, doi: 10.1063/1.1721956. [Link]

Bredehoeft, J. D., 1967: Response of well-aquifer systems to earth tides. J. Geophys. Res., 72, 3075-3087, doi: 10.1029/ JZ072i012p03075. [Link]

Central Weather Bureau, 2006: Earthquake report \#95106 and 95107, 95-12-26.

CGS (Central Geological Survey), 2002: Groundwater observation well network in Taiwan area: Hydrogeologic investigation in the Pingtung plain, CGS Rep., 1009102131. (in Chinese)

Chia, Y. P., Y. S. Wang, J. J. Chiu, and C. W. Liu, 2001: Changes of groundwater level due to the 1999 Chi-Chi earthquake in the Choshui River alluvial fan in Taiwan. Bull. Seismol. Soc. Am., 91, 1062-1068, doi: 10.1785/0120000726. [Link]

Cooper, H. H., Jr., J. D. Bredehoeft, I. S. Papadopulos, and R. R. Bennett, 1965: The response of well-aquifer systems to seismic waves. J. Geophys. Res., 70, 3915-3926, doi: 10.1029/JZ070i016p03915. [Link] 
Ge, S. and S. C. Stover, 2000: Hydrodynamic response to strikeand dip-slip faulting in a half space. J. Geophys. Res., 105, 25513-25524, doi: 10.1029/2000JB900233. [Link]

Liu, L. B., E. Roeloffs, and X. Y. Zheng, 1989: Seismically induced water level fluctuations in the Wali well, Beijing, China. J. Geophys. Res., 94, 9453-9462, doi: 10.1029/JB 094iB07p09453. [Link]

Muir-Wood, R. and G. C. P. King, 1993: Hydrologic signatures of earthquake strain. J. Geophys. Res., 98, 22035-22068, doi: 10.1029/93JB02219. [Link]

National Science and Technology Center for Disaster Reduction (NCDR) and National Center for Research on Earthquake Engineering (NCREE), 2006: The preliminary reconnaissance report of 2006 Hengchun earthquake. (in Chinese)

Ohno, M., H. Wakita, and K. Kanjo, 1997: A water well sensitive to seismic waves. Geophys. Res. Lett., 24, 691-694, doi: 10.1029/97GL00471. [Link]

Palciauskas, V. V. and P. A. Domenico, 1989: Fluid pressure in deforming porous rocks. Water Resour. Res., 25, 203-213, doi: 10.1029/WR025i002p00203. [Link]
Rice, J. R. and M. P. Cleary, 1976: Some basic stress diffusion solutions for fluid-saturated elastic porous media with compressible constituents. Rev. Geophys., 14, 227-241, doi: 10.1029/RG014i002p00227. [Link]

Roeloffs, E. A., 1988: Hydrologic precursors to earthquakes: A review. Pure Appl. Geophys., 126, 177-209, doi: 10.1007/ BF00878996. [Link]

Roeloffs, E. A., 1998: Persistent water level changes in a well near Parkfield, California, due to local and distant earthquakes. J. Geophys. Res., 103, 869-889, doi: 10.1029/97 JB02335. [Link]

Roeloffs, E. A. and E. Quilty, 1997: Water Level and Strain Changes Preceding and Following the August 4, 1985 Kettleman Hills, California, Earthquake. Pure Appl. Geophys., 149, 21-60, doi: 10.1007/BF00945160. [Link]

US Geologic Survey, 2006: Magnitude 7.1 - Taiwan region, Earthquake Hazards Program 2006-12-26.

Wakita, H., 1975: Water wells as possible indicators of tectonic strain. Science, 189, 553-555, doi: 10.1126/science.189. 4202.553. [Link]

\section{APPENDIX}

Appendix 1. Supplementary information of coseismic groundwater level changes.

\begin{tabular}{lcccc}
\hline Station Name & Well Name & Coseismic Change (cm) & TM_X & TM_Y \\
\hline Shifen & SF2 & -3 & 154146 & 2556442 \\
Shaying & SY2 & -8 & 173545 & 2570238 \\
Shaying & SY4 & -7 & 173545 & 2570238 \\
Dawen & DW1 & 2 & 162586 & 2561292 \\
Dawen & DW2 & -3 & 162586 & 2561292 \\
Dawen & DW3 & -2 & 162586 & 2561292 \\
Dacer & DC1 & 6 & 181950 & 2514800 \\
Littlexin & LS2 & -2 & 178501 & 2558459 \\
Wujia & WJ1 & -14 & 181028 & 2540128 \\
Wuwoods & WL2 & -5 & 176549 & 2518073 \\
Wuwoods & WL3 & -3 & 176549 & 2518073 \\
Jende & JD2 & -3 & 172760 & 2540572 \\
Liujia & LJ1 & -2 & 182708 & 2569605 \\
Liujia & LJ2 & -8 & 182708 & 2569605 \\
Tainan & TN1 & 7 & 160526 & 2548099 \\
Tainan & TN2 & 2 & 160526 & 2548099 \\
Yonghua & YH1 & 4 & 169575 & 2524125 \\
Anping & AP1 & 2 & 163950 & 2544815 \\
Anching & AC1 & 1 & 166368 & 2549095 \\
Anching & AC2 & -1 & 166368 & 2549095 \\
\hline
\end{tabular}


Appendix 1. (Continued)

\begin{tabular}{|c|c|c|c|c|}
\hline Station Name & Well Name & Coseismic Change (cm) & TM_X & TM_Y \\
\hline Anching & $\mathrm{AC} 3$ & -5 & 166368 & 2549095 \\
\hline Anching & $\mathrm{AC} 4$ & -14 & 166368 & 2549095 \\
\hline Naba & NB2 & -4 & 182416 & 2552332 \\
\hline Guantian & GT3 & -3 & 181773 & 2565588 \\
\hline Gangshan & GS1 & 11 & 174100 & 2524520 \\
\hline Nanke & NK2 & -9 & 175430 & 2556230 \\
\hline Nanke & NK3 & -3 & 175430 & 2556230 \\
\hline Liuing & LI2 & -6 & 178870 & 2575008 \\
\hline Jian & JA2 & -7 & 171010 & 2561511 \\
\hline Gangwei & GW3 & -6 & 167942 & 2567431 \\
\hline Ganghe & GH3 & -7 & 181125 & 2496875 \\
\hline Shanwa & SW1 & 3 & 176200 & 2559721 \\
\hline Shanwa & SW2 & -2 & 176200 & 2559721 \\
\hline Newshi & NS1 & -17 & 177117 & 2553431 \\
\hline Zongye & ZY3 & -6 & 174375 & 2565395 \\
\hline Yancheng & $\mathrm{YC} 1$ & 9 & 175440 & 2502825 \\
\hline Yancheng & $\mathrm{YC} 3$ & -3 & 175440 & 2502825 \\
\hline Jiuru & JR1 & -1 & 196776 & 2515370 \\
\hline Jiuqu & JQ1 & -29 & 190015 & 2506507 \\
\hline Jiuqu & JQ2 & -23 & 190015 & 2506507 \\
\hline Dahu & DH1 & 2 & 200368 & 2497500 \\
\hline Dahu & DH2 & 14 & 200368 & 2497500 \\
\hline Datan & DT1 & 5 & 197221 & 2484469 \\
\hline Datan & DT2 & -4 & 197221 & 2484469 \\
\hline Dashu & DS3 & -5 & 191135 & 2510159 \\
\hline Dashu & DS4 & -3 & 191135 & 2510159 \\
\hline Daxiang & DX1 & 5 & 210206 & 2481360 \\
\hline Daxiang & DX2 & 7 & 210206 & 2481360 \\
\hline Chongjeng & CJ1 & -8 & 185015 & 2503504 \\
\hline Chongjeng & $\mathrm{CJ} 2$ & -5 & 185015 & 2503504 \\
\hline Neipu & NP1 & 22 & 204588 & 2501296 \\
\hline Neipu & NP2 & 10 & 204588 & 2501296 \\
\hline Shuidiliao & SDL1 & 13 & 207650 & 2475845 \\
\hline Yongfang & YF2 & -4 & 186942 & 2500950 \\
\hline Yongfang & YF3 & -12 & 186942 & 2500950 \\
\hline Xishi & XS1 & 26 & 200397 & 2502704 \\
\hline Xishi & XS2 & 25 & 200397 & 2502704 \\
\hline Xishi & $\mathrm{XS} 3$ & 21 & 200397 & 2502704 \\
\hline Xishi & XS4 & 12 & 200397 & 2502704 \\
\hline Tzeshan & TS1 & 6 & 209521 & 2499542 \\
\hline
\end{tabular}


Appendix 1. (Continued)

\begin{tabular}{|c|c|c|c|c|}
\hline Station Name & Well Name & Coseismic Change (cm) & TM_X & TM_Y \\
\hline Tzeshan & TS3 & -18 & 209521 & 2499542 \\
\hline Fangshan & FS1 & 3 & 210142 & 2470440 \\
\hline Fangliao & FL1 & 4 & 207476 & 2479160 \\
\hline Donggan & DG1 & 53 & 193156 & 2485971 \\
\hline Donggan & DG2 & 29 & 193156 & 2485971 \\
\hline Donggan & DG3 & 50 & 193156 & 2485971 \\
\hline Linyuan & LY1 & 7 & 186809 & 2490130 \\
\hline Qianjin & QJ1 & -3 & 193652 & 2505845 \\
\hline Jianxing & $\mathrm{JX} 1$ & 5 & 204395 & 2507086 \\
\hline Jianxing & $\mathrm{JX} 2$ & 7 & 204395 & 2507086 \\
\hline Chaoming & CM1 & 17 & 188414 & 2493802 \\
\hline Chaoming & $\mathrm{CM} 2$ & -9 & 188414 & 2493802 \\
\hline Chaoming & $\mathrm{CM} 3$ & -10 & 188414 & 2493802 \\
\hline Chaoming & CM4 & -10 & 188414 & 2493802 \\
\hline Sheliao & SL1 & 14 & 219363 & 2440038 \\
\hline Sheliao & SL2 & 54 & 219363 & 2440038 \\
\hline Sheliao & SL3 & 24 & 219363 & 2440038 \\
\hline Taimount & TM2 & 2 & 209266 & 2521392 \\
\hline Haifeng & HF2 & 8 & 198476 & 2511130 \\
\hline Chifeng & CF2 & 16 & 197178 & 2480938 \\
\hline Chifeng & CF3 & 22 & 197178 & 2480938 \\
\hline Chifeng & CF4 & 23 & 197178 & 2480938 \\
\hline Chingxi & $\mathrm{CS} 3$ & -3 & 194408 & 2506330 \\
\hline Pengtsuo & PT2 & 2 & 201104 & 2515658 \\
\hline Gangdong & GD3 & -4 & 195798 & 2490241 \\
\hline Gangdong & GD4 & -7 & 195798 & 2490241 \\
\hline Wenfeng & WF2 & 34 & 200355 & 2479195 \\
\hline Singbei & SB1 & 49 & 202895 & 2485957 \\
\hline Singbei & SB2 & 29 & 202895 & 2485957 \\
\hline Singbei & SB4 & 9 & 202895 & 2485957 \\
\hline Newyuan & NY2 & -4 & 192774 & 2491800 \\
\hline Shipu & SP3 & -3 & 191978 & 2513893 \\
\hline Wandan & WD2 & 9 & 194540 & 2501970 \\
\hline Wandan & WD3 & -3 & 194540 & 2501970 \\
\hline Wanlong & WL2 & 10 & 206802 & 2490112 \\
\hline Wanrun & WR1 & 37 & 207502 & 2497136 \\
\hline Wanrun & WR2 & 10 & 207502 & 2497136 \\
\hline Majia & MJ3 & 2 & 208976 & 2511539 \\
\hline Shangtan & ST1 & 14 & 208707 & 2486714 \\
\hline Shangtan & ST2 & -2 & 208707 & 2486714 \\
\hline
\end{tabular}


324

Chia et al.

Appendix 1. (Continued)

\begin{tabular}{lcccc}
\hline Station Name & Well Name & Coseismic Change (cm) & TM_X & TM_Y \\
\hline Texing & TX3 & 28 & 207000 & 2474613 \\
Tsaojoe & TJ2 & 11 & 202232 & 2492984 \\
Chaoliao & CL3 & -4 & 190004 & 2496500 \\
Fanhua & FH2 & 1 & 205264 & 2511656 \\
Guanfu & GF2 & 2 & 209883 & 2518620 \\
Yanpu & YP2 & 3 & 205622 & 2517240 \\
Fengming & FM1 & 4 & 182982 & 2490949 \\
\hline
\end{tabular}

